\title{
Screening for atrial fibrillation with baseline and intermittent ECG recording in an out-of-hospital population
}

\author{
Tijn Hendrikx ${ }^{1 *}$, Rolf Hörnsten ${ }^{2}$, Mårten Rosenqvist ${ }^{3}$ and Herbert Sandström ${ }^{1}$
}

\begin{abstract}
Background: the objective of this study is to investigate the detection rate of undiagnosed atrial fibrillation (AF) with short intermittent ECG recordings during four weeks among out-of-hospital patients, having at least one additional risk factor $\left(\mathrm{CHADS}_{2}\right)$ for stroke.

Method: Design: Cross-sectional study. Setting: Eight family practice centres and two hospital-based out-patient clinics in Sweden. Subjects: 989 out-of-hospital patients, without known AF, having one or more risk factors associated with stroke $\left(\mathrm{CHADS}_{2}\right)$. Interventions: All individuals were asked to perform 10-second handheld ECG recordings during 28 days, twice daily and when having palpitations. Main outcome measures: Episodes of AF on handheld ECG recordings were defined as irregular supraventricular extrasystoles in series with a duration of 10 seconds.

Results: 928 patients completed registration. AF was found in 35 of 928 patients; 3.8\% (95\% confidence interval [Cl] 2.7-5.2). These 35 patients had a mean age of 70.7 years (SD \pm 7.7 ; range 53-85) and a median $\mathrm{CHADS}_{2}$ of 2 (range $1-4)$.

Conclusions: Intermittent handheld ECG recording over a four week period had a detection rate of 3.8\% newly diagnosed AF, in a population of 928 out-of-hospital patients having at least one additional risk factor for stroke. Intermittent handheld ECG registration is a feasible method to detect AF in patients with an increased risk of stroke in whom oral anticoagulation (OAC) treatment is indicated.
\end{abstract}

Keywords: Arrhythmia, Atrial fibrillation, Handheld ECG, Stroke prevention, Screening

\section{Background}

Atrial fibrillation/flutter (AF) is the most common type of arrhythmia occurring in 1-2\% of the adult population. With increasing age the prevalence of AF increases. Approximately $5 \%$ of the population over 65 years and $10 \%$ of the population over 80 years has AF [1-5]. A recent Swedish study shows an even higher overall prevalence of $2.5 \%$ and a prevalence of $13.8 \%$ in those over 80 years [6].

Occurrence of AF constitutes in itself an independent risk factor for stroke [7], and with other concurrent risk factors, congestive heart failure, hypertension,

\footnotetext{
* Correspondence: tijn.hendrikx@fammed.umu.se

'Department of Public Health and Clinical Medicine, Family Medicine, Umeå University, SE-901 87, Umeå, Sweden

Full list of author information is available at the end of the article
}

age $\geq 75$ years, diabetes and earlier stroke $\left(\mathrm{CHADS}_{2}\right.$ score), this risk is additionally increased [8,9]. In AF patients with a $\mathrm{CHADS}_{2}$ score of $\geq 1$, treatment with oral anticoagulation (OAC) should be considered. In AF patients with a $\mathrm{CHADS}_{2}$ score of $\geq 2$ chronic OAC is recommended to prevent stroke [9].

AF was found in 28.7\% (of 152 746) Swedish stroke patients at admission to hospital 2001-2008 [10]. Since $\mathrm{AF}$ is often asymptomatic it may remain undiagnosed for a long time and many of these patients will not receive OAC before suffering a stroke [11]. It has been estimated that only one in ten paroxysms of AF are symptomatic $[12,13]$. Several studies have shown that patients with paroxysmal AF have the same stroke incidence as patients with permanent AF [14-16].

\section{Biomed Central}


It has been estimated that up to $8 \%$ of stroke patients without known AF have episodes of asymptomatic AF beyond that detected by physical examination and initial ECG during hospital admission for acute ischemic stroke [17-19]. A recent study shows that intermittent handheld ECG recording after carrying out Holter ECG substantially improves the detection of asymptomatic atrial fibrillation (AF) in post-stroke patients [20].

AF in the general population is traditionally detected with pulse registration/palpation, 12-lead resting ECG [21-23] or 24-hour Holter/Event recorder ECG [24], but these methods have a relatively low sensitivity for detection of asymptomatic AF. As a result the prevalence of undiagnosed AF in the general population is not well known.

The objective of this study is to estimate the detection rate of undiagnosed AF among out-of-hospital patients, having at least one additional risk factor $\left(\mathrm{CHADS}_{2}\right)$ for stroke, using intermittent 10-second ECG recording during 28 days with a handheld device.

\section{Methods}

\section{Design, study population and setting}

In this cross-sectional study patients from eight family practice centres and two hospital-based out-patient clinics in Sweden, having one or more risk factors associated with stroke $\left(\mathrm{CHADS}_{2}\right.$ score), without known AF, were identified from physicians' and nurses' surgery lists and included consecutively.

\section{Inclusion period}

The inclusion period extended from May 2007 until June 2011.

\section{Intervention}

Inclusion criteria: one or more risk factors associated with stroke $\left(\mathrm{CHADS}_{2}\right.$ score). Exclusion criteria: known $\mathrm{AF}$, impaired cognitive function or other functional impairments that prevent the use of the handheld device. When AF was detected during the study an additional review of the patient's medical record and existing ECGs five years back in time was done to reveal unreported previous episodes of AF. Patients with such episodes of AF were excluded.

After giving informed consent patients were instructed to perform a 10 second handheld ECG (Zenicor EKG ${ }^{\oplus}$ ). When AF was detected at the first registration, patients were referred for treatment without further registrations. If no AF was seen at the first registration, patients were asked to perform a similar 10-second handheld ECG (Zenicor $\mathrm{EKG}^{\odot}$ ) registration during 28 days, twice daily (morning and evening) and when having palpitations. After every registration the recording was transmitted by the patient via phone to an internet-based central database. ECG registrations were evaluated at least once a week by a study nurse and when in doubt the ECG was additionally checked by a single physician, having the possibility to contact a cardiologist in uncertain cases. Patients with detected AF were referred for treatment in accordance with national guidelines to the patients' regular family physician or to a cardiologist. Patients with less than 20 registrations were excluded. (For additional information see Figure 1: study flowchart).

\section{Outcome measures}

We defined episodes of AF on handheld ECG recordings as irregular supraventricular extrasystoles in series with a duration of 10 seconds. Ambiguous recordings, showing repetitive irregular supraventricular extrasystoles (SVES) less than 10 seconds, were referred for an additional 24-hour Holter ECG. AF on Holter was defined by at least 10 seconds showing irregular rhythm without sinus P-waves.

Paroxysmal AF was defined as self-terminating, usually within seven days. Persistent AF was defined as an AF episode that either lasts longer than 7 days (but less than a year) or requires termination by cardioversion, either with drugs or by direct current cardioversion (DCC) [9].

\section{The device}

ECG recordings were performed using a handheld device, Zenicor $E K G^{\oplus}$, which via both thumbs registers a bipolar extremity lead I ECG during 10 seconds. After each registration the recording was transmitted by the patient via phone to a web-based central database. The ability to give the correct diagnosis of AF compared to 12-lead ECG has shown a sensitivity of $96 \%$ and a specificity of $92 \%$ [25]. A detailed technical description of the device, and its performance is published elsewhere [25]. (An example of AF as recorded with the handheld ECG device is given in Figure 2. Figure 3 shows a photo of the handheld ECG device).

\section{Statistics}

The statistics of this study were mainly descriptive. Continuous variables were presented with mean, standard deviation (SD) and range (minimum and maximum) whereas categorical variables were presented with count and percentage and, where appropriate, a 95\% confidence interval. Pearson Chi Square test was used to test for differences in AF detection rate for gender, age categories and $\mathrm{CHADS}_{2}$ risk factors. To evaluate possible differences in the number of registrations, age and total $\mathrm{CHADS}_{2}$ risk score between individuals with and without detected AF, the Mann-Whitney U test was used. SPSS Statistics 19.0 (IBM Corporation, Route 100 Somer, NY 10589) was used for all calculations. The level of significance was set at 0.05 , two-sided. The sample size was 


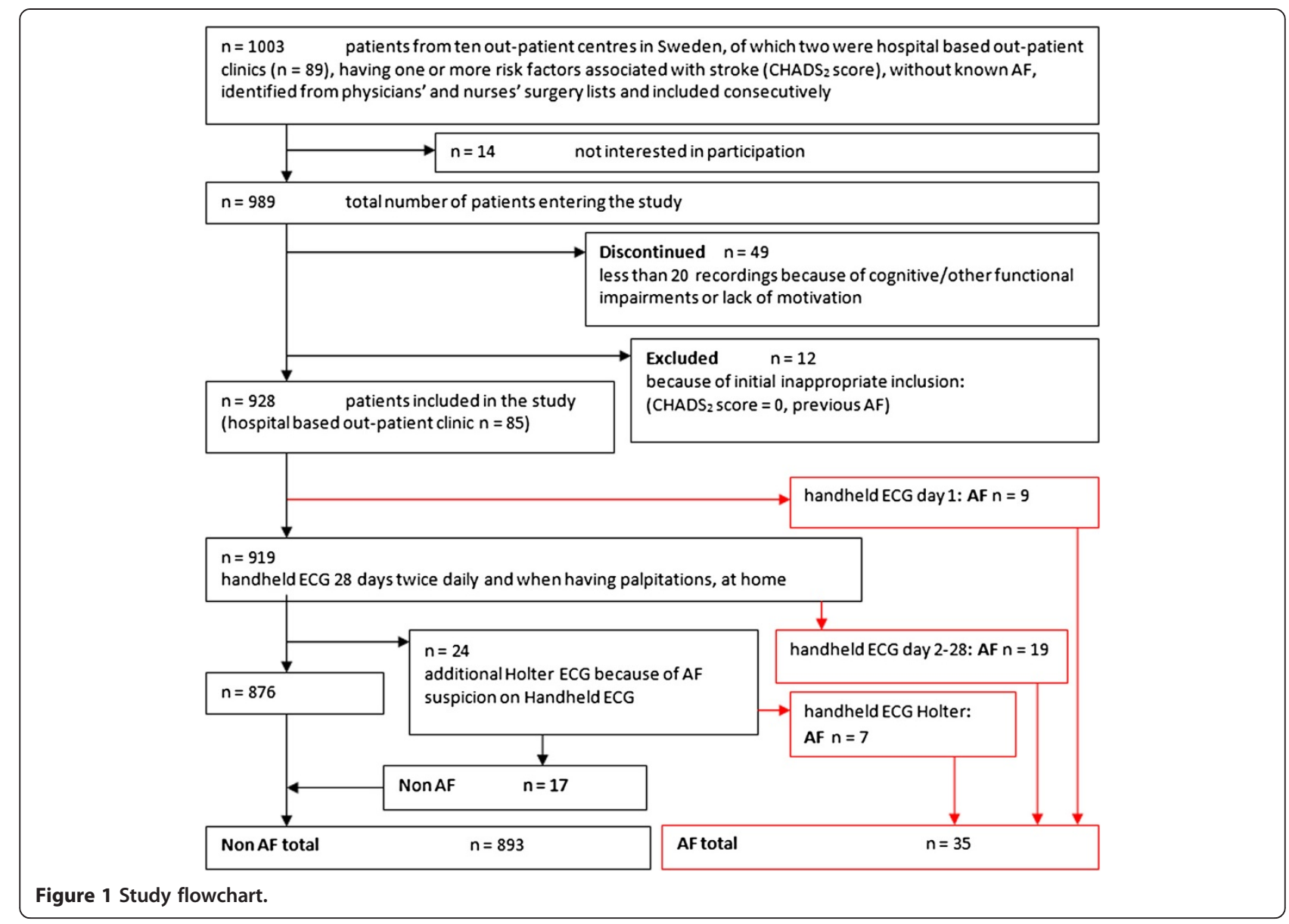

based on the hypothesis of finding 4\% AF. Given approximately 1000 patients this would yield a 95\% confidence interval of $\pm 1 \%$, which was deemed narrow enough to answer the objective.

\section{Ethical considerations}

The study was approved by the Regional Ethics Committee (Dnr 07-051 M). All participating patients gave written informed consent.

\section{Results}

\section{Demographics}

A total of 989 patients, 491 men and 498 women, entered the study. Forty-nine patients with fewer than 20 recordings did not complete registration because of technical or medical problems. Twelve patients were excluded due to initial inappropriate inclusion. Clinical characteristics of the remaining 928 patients are displayed in Table 1. The mean number of registrations per patients, with respect to a recommended number of 56 registrations, was

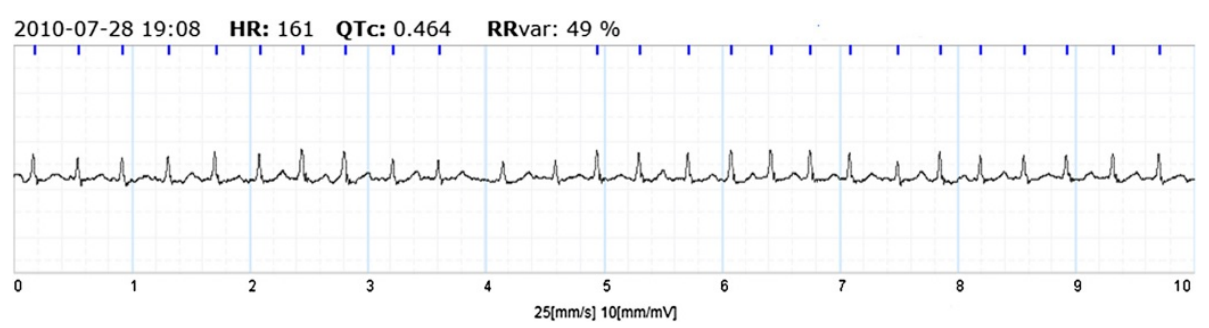

Figure 2 Example of registration of AF with handheld ECG. 


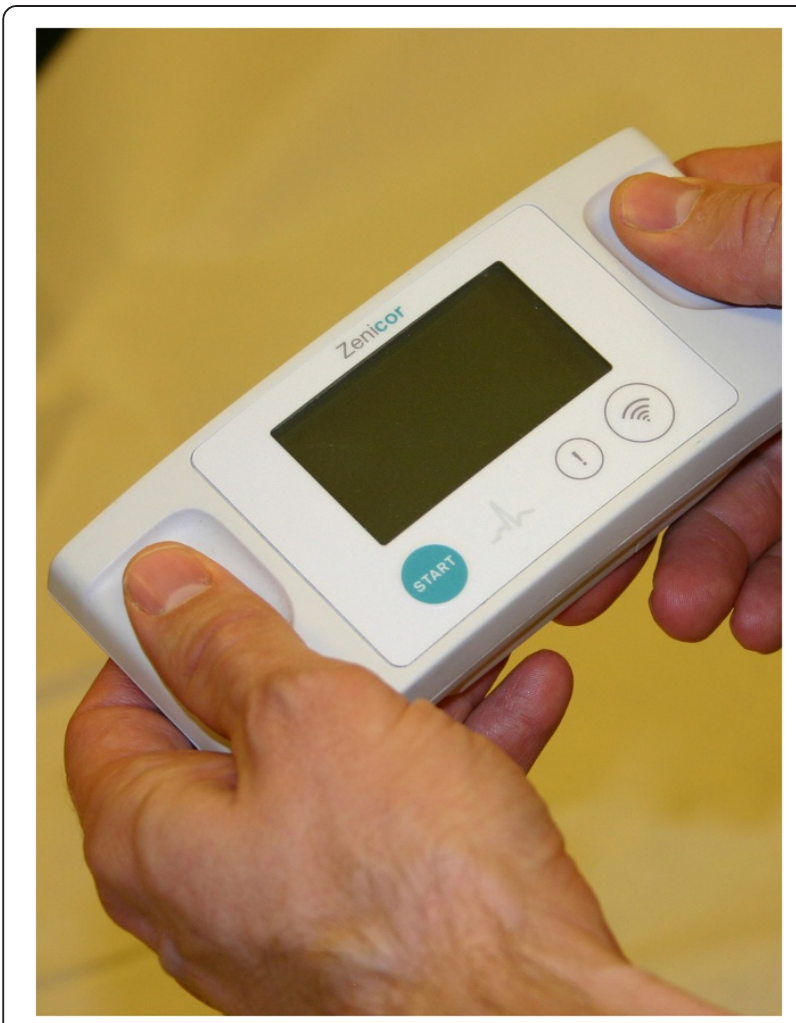

Figure 3 Photo of the handheld ECG device.

55.4 registrations $(\mathrm{SD} \pm 11.2$ and range $1-125)$. There was no statistical correlation between AF detection and the number of registrations (Mann-Whitney $U$ test, $\mathrm{P}=0.442$ ).

\section{Detection of AF and AF characteristics}

Analysis of our data showed newly diagnosed AF in 35 of these 928 patients (3.8\% (95\% confidence interval [CI] 2.7-5.2)). Characteristics of AF patients are displayed in Table 1 and a study flowchart (Figure 1). Twenty-eight of these AF patients were detected with handheld ECG alone; nine patients at the time of their first handheld ECG recording, nineteen patients after 28 days of intermittent handheld ECG recording. Follow-up showed that of nine patients discovered at day one six had persistent AF and three paroxysmal AF. One additional patient who continued with registrations after day 28 had one AF episode at day 38. As this was not detected within 28 days he was not counted as newly diagnosed AF within the study framework. Seven patients showing episodes of repetitive irregular supraventricular extrasystoles (SVES) less than 10 seconds on handheld registrations were diagnosed with AF after an additional 24-hour Holter ECG.

Eighty percent of patients with detected AF were aged $\geq 65$ years. The AF detection rate for patients $<65$ years was $2.9 \%$ and for patients $\geq 65$ years $4.1 \%$
(Pearson Chi Square test, $\mathrm{P}=0.404$ ). The patients in this study had in general low $\mathrm{CHADS}_{2}$ scores with a median of 2 (range 1-5). Slightly higher detection rates for AF could be seen among those with $\mathrm{CHADS}_{2} \geq 2$ compared to those with a score of 1 , but no significant differences were seen (Pearson Chi Square test, $\mathrm{P}=0.351$ ). More male than female patients were discovered $(4.6 \%$ and $3.0 \%$ respectively), but this difference was not significant (Pearson Chi Square test, $\mathrm{P}=0.218$ ).

In $\mathrm{AF}$ patients $\mathrm{AF}$ was recorded in $33.7 \%$ of registrations on average ( $\mathrm{SD} \pm 41.1$ and range $1.3 \%-100 \%)$. Characteristics of AF registrations are displayed in Table 2.

There was no difference regarding whether AF occurred in the morning or the evening. Only $12.4 \%$ of AF registrations were related to symptoms. On average AF was diagnosed after 7.3 days $(\mathrm{SD} \pm 7.6$; range $1-28$ ). (Time to detection is illustrated in Figure 4). More than eighty percent of AF patients discovered with handheld ECG were found within 14 days. Six patients had a persistent AF. Four patients had atrial flutter. In case of typical p-wave morphology, as in atrial flutter, diagnosis was confirmed with 12-lead ECG or Holter ECG.

\section{Additional holter ECG investigation}

Thirty additional Holter investigations were done. Twentyfour Holter recordings were made because of suspected AF on handheld ECG and resulted in seven more AF diagnoses. Four of these patients had episodes of more than 30 seconds on Holter; three had episodes of more than 10 seconds but less than 30 seconds. Six Holter investigations were done because of suspected brady-arrhythmias. Five patients received a pacemaker because of diagnosis of AV block II-III or sinus arrest. All five patients had a $\mathrm{CHADS}_{2}$ of 2 , mainly hypertension and age $\geq 75$. Three of them had ischemic heart disease. Their average age was 74.4 years with a range of $58-85$.

\section{Discussion}

Opportunistic screening in an out-of-hospital population with at least one risk factor for stroke $\left(\mathrm{CHADS}_{2}\right)$ resulted in detection of $3.8 \%$ previously unknown AF, higher than in previous studies of out-of-hospital populations [21-23]. These results, if replicated in other studies, show the possibilities for the use of intermittent ECG registration as a screening instrument for detection of AF. A detection rate of $3.8 \%$ newly diagnosed AF is high, especially when considering that the study population was relatively young and healthy with few $\mathrm{CHADS}_{2}$ risk factors. AF patients were on average slightly older and had slightly higher $\mathrm{CHADS}_{2}$ risk factors than nonAF patients, but no statistically significant clinical differences were seen.

A survey of previously published studies did not reveal data comparing the efficiency of intermittent ECG 
Table 1 Characteristics of the total study population, AF patients and non-AF patients

\begin{tabular}{|c|c|c|c|c|c|c|c|c|c|c|}
\hline & \multicolumn{3}{|c|}{ Total population } & $\mathrm{AF}$ & & & \multicolumn{3}{|l|}{ Non-AF } & P-value \\
\hline & & & & & detection rate (\%) & $95 \% \mathrm{Cl}$ & & & & \\
\hline Total, $\mathbf{n}$ & \multicolumn{3}{|l|}{928} & 35 & $3.8 \%$ & $(2.7-5.2)$ & \multicolumn{3}{|l|}{893} & \\
\hline Men, n (\%) & \multicolumn{3}{|c|}{$462(49.8 \%)$} & $21(60.0 \%)$ & $4.6 \%$ & $(3.0-6.8)$ & \multicolumn{2}{|c|}{$441(49.4 \%)$} & & 0.218 \\
\hline Women, n (\%) & \multicolumn{3}{|c|}{$466(50.2 \%)$} & $14(40.0 \%)$ & $3.0 \%$ & $(1.8-5.0)$ & \multicolumn{2}{|c|}{$452(50.6 \%)$} & & \\
\hline Age < 65 years, n (\%) & \multicolumn{3}{|c|}{$242(26.1 \%)$} & $7(20.0 \%)$ & $2.9 \%$ & $(1.4-5.8)$ & \multicolumn{2}{|c|}{$235(26.3 \%)$} & & 0.404 \\
\hline Age $\geq 65$ years, $n$ (\%) & \multicolumn{3}{|c|}{$686(73.9 \%)$} & $28(80.0 \%)$ & $4.1 \%$ & $(2.8-5.8)$ & \multicolumn{3}{|c|}{658 (73.7\%) } & \\
\hline CHADS2 = 1, n (\%) & \multicolumn{3}{|c|}{$415(44.7 \%)$} & $13(37.1 \%)$ & $3.1 \%$ & $(1.7-5.1)$ & \multicolumn{2}{|c|}{$403(45.1 \%)$} & & 0.351 \\
\hline CHADS2 $\geq 2, \mathrm{n}(\%)$ & \multicolumn{3}{|c|}{$513(55.3 \%)$} & $22(62.9 \%)$ & $4.3 \%$ & $(2.8-6.3)$ & \multicolumn{3}{|c|}{$490(54.9 \%)$} & \\
\hline CHF, n (\%) & \multicolumn{3}{|c|}{$34(3.7 \%)$} & $1(2.9 \%)$ & $2.9 \%$ & $(0.7-14.9)$ & \multicolumn{3}{|c|}{$33(3.7 \%)$} & 0.796 \\
\hline HT, n (\%) & \multicolumn{3}{|c|}{$838(90.3 \%)$} & $31(88.6 \%)$ & $3.7 \%$ & $(2.6-5.2)$ & \multicolumn{3}{|c|}{807 (90.4\%) } & 0.724 \\
\hline Age $\geq 75$ y, n (\%) & \multicolumn{3}{|c|}{$326(35.0 \%)$} & $13(37.1 \%)$ & $4.0 \%$ & $(2.6-7.1)$ & \multicolumn{3}{|c|}{$313(35.1 \%)$} & 0.799 \\
\hline $\mathrm{DM}, \mathrm{n}(\%)$ & \multicolumn{3}{|c|}{$293(31.6 \%)$} & $12(34.3 \%)$ & $4.1 \%$ & $(2.4-7.0)$ & \multicolumn{3}{|c|}{$281(31.5 \%)$} & 0.725 \\
\hline ES, n (\%) & \multicolumn{3}{|c|}{$80(8.6 \%)$} & $4(11.4 \%)$ & $5.0 \%$ & $(2.0-12.2)$ & \multicolumn{3}{|c|}{$76(8.5 \%)$} & 0.546 \\
\hline \multirow[t]{3}{*}{ IHD*, n (\%) } & \multicolumn{3}{|c|}{$184(19.8 \%)$} & $5(14.3 \%)$ & $2.7 \%$ & $(1.2-6.2)$ & \multicolumn{3}{|c|}{$179(20.0 \%)$} & 0.402 \\
\hline & \multicolumn{3}{|c|}{ Total population } & \multicolumn{3}{|l|}{$\mathrm{AF}$} & \multicolumn{3}{|c|}{ Non-AF } & \\
\hline & Mean & $S D$ & Range & Mean & $S D$ & Range & Mean & $S D$ & Range & P-value \\
\hline Number of ECG registrations, $n$ & 55.4 & \pm 11.2 & $1-125$ & 50.3 & \pm 22.1 & $1-96$ & 55.6 & \pm 10.5 & $20-125$ & 0.442 \\
\hline \multirow[t]{2}{*}{ Age, y } & 69.8 & \pm 9.4 & $33-89$ & 70.7 & \pm 7.7 & $53-85$ & 69.8 & \pm 9.4 & $33-89$ & 0.679 \\
\hline & Mediar & & Range & Median & & Range & Median & & Range & \\
\hline $\mathrm{CHADS}_{2}$ total & 2 & & $1-5$ & 2 & & $1-4$ & 2 & & $1-5$ & 0.451 \\
\hline
\end{tabular}

CHF Congestive heart failure, HT Hypertension, DM Diabetes mellitus, ES Earlier stroke/TIA, IHD Ischemic heart disease (* not included in CHADS2). P-values compare AF with non-AF patients. Participants can have more than one co-morbidity.

recording with other screening methods for the detection of AF in an out-of-hospital population. A British multicentre randomized controlled trial using systematic and/ or opportunistic screening with pulse control and 12-lead ECG to detect AF among people over 65 years found incidences of less than $2 \%$ newly diagnosed AF for all methods (even when including patients detected outside the screening programme), within a year of screening $[21,22]$. Another study screening of a general practice population using pulse assessment found about 1\% previously unknown AF [23]. Studies of post-stroke patients estimated a prevalence of $3.8-8.4 \%$ previously undiagnosed AF using 24-hour Holter and Event loop recorder ECG [17-19]. A recent Swedish study shows that intermittent handheld ECG recording compared with 24-hour Holter ECG substantially improves the detection of silent paroxysmal atrial fibrillation (AF) in post-stroke patients [20]. Continuous monitoring during a follow-up of $1.1 \pm$ 0.7 years with an implanted device resulted in detection of $30 \%$ previously unknown AF, in a population of patients with risk factors for stroke, who had recently received a pacemaker, implantable cardioverter defibrillator or cardiac resynchronization therapy device [26]. Using such implantable devices for screening in large out-of-hospital populations is at present not suitable for economic reasons. Other devices, e.g. patch-based appliances with the
Table 2 AF characteristics of newly diagnosed AF patients

\begin{tabular}{|c|c|c|c|}
\hline Paroxysmal AF, n (\%) & 29 & $(82.9 \%)$ & \\
\hline Persistent AF, n (\%) & 6 & $(17.1 \%)$ & \\
\hline Atrial fibrillation, $\mathrm{n}(\%)$ & 31 & $(88.6 \%)$ & \\
\hline Atrial flutter, n (\%) & 4 & $(11.4 \%)$ & \\
\hline \multicolumn{4}{|l|}{$\begin{array}{l}\text { Time to AF detection with } \\
\text { Handheld ECG }(n=28)\end{array}$} \\
\hline Day 1 & 9 & (32.1\%) & \\
\hline Day 2-14, n (\%) & 14 & $(50.0 \%)$ & \\
\hline Day $15-28$, n (\%) & 5 & $(17.9 \%)$ & \\
\hline \multirow{2}{*}{$\begin{array}{l}\text { Diagnosis after additional } \\
\text { Holter, } \mathrm{n}\end{array}$} & 7 & & \\
\hline & Mean & $S D$ & Range \\
\hline $\begin{array}{l}\text { AF registration (\% of total } \\
\text { registration time) }\end{array}$ & $33.7 \%$ & \pm 41.1 & $1.3 \%-100 \%$ \\
\hline $\begin{array}{l}\mathrm{AF} \text { at morning registration (\% of } \\
\mathrm{AF} \text { registrations) }\end{array}$ & $47.7 \%$ & \pm 34.5 & $0 \%-100 \%$ \\
\hline $\begin{array}{l}\text { Symptoms registered at } \mathrm{AF} \\
\text { episode (\% of AF registrations) }\end{array}$ & $12.4 \%$ & \pm 28.7 & $0 \%-100 \%$ \\
\hline Time to first AF episode (days) & 7.3 & \pm 7.6 & $1-28$ \\
\hline $\begin{array}{l}\text { Mean heart rate during AF } \\
\text { episodes (beats/minute) }\end{array}$ & 105 & \pm 26.9 & $60-160$ \\
\hline
\end{tabular}




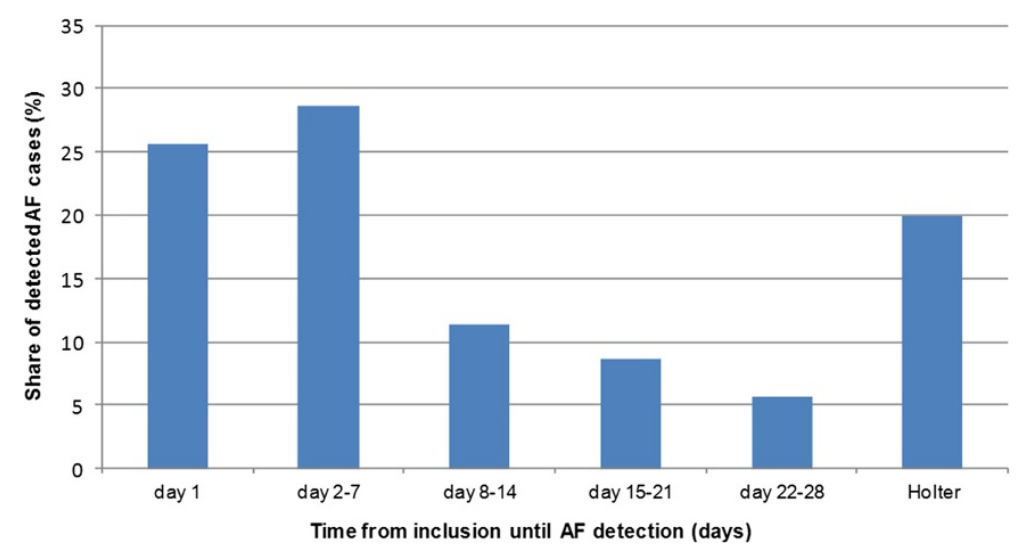

Figure 4 Time from inclusion until AF detection.

possibility of long-term continuous recording, could however become an alternative for screening in large out-of-hospital populations [27].

The study design does not allow for any assessment of how representative the population is. The detection rate of $\mathrm{AF}$, mean age and mean $\mathrm{CHADS}_{2}$ were comparable at all ten centres and this together with the size of the study population, consecutive inclusion, a very high participation rate and low drop-out increases the likeliness of representativeness.

\section{Device and method}

The novelty in this study compared to other studies screening for AF is both the device itself and the screening method of prolonged intermittent recording for four weeks, both regularly and when having symptoms.

Handheld ECG in combination with the chosen screening method has advantages compared to other, traditional screening instruments. The device is small and involves almost no limitation to the mobility of the patients. Registrations are easy to perform and compliance is high, as supported by the results of the present study where $95 \%$ of all included patients had sufficient technical recordings. The ECG recording can immediately be transmitted to a website and assessed directly. Since there was no comparison group, cost-effectiveness cannot be addressed. The cost per screened patient using this method of screening is less than $€ 100$.

\section{Future screening: high compliance; shorter screening period?}

The high compliance rate using this method indicates that it is feasible as a screening instrument for AF. More than $80 \%$ of AF diagnoses with handheld ECG were found within 14 days, suggesting that the registration period can be shortened without losing too much information. A major screening study has been launched in which 25000 Swedes aged 75 and 76 years are randomized either to participate in a 14-day screening programme using 30second handheld intermittent ECG recording to detect asymptomatic $\mathrm{AF}$, or to act as control group [28].

\section{Detection of patients with conduction system disease}

Six Holter investigations were done because of suspected brady-arrhythmias and five patients received a pacemaker because of diagnosis of AV block II-III or sinus arrest. All five patients were symptomatic, reporting dizziness and syncope but had not contacted healthcare previously. They were on average slightly older, had higher $\mathrm{CHADS}_{2}$ scores and significantly more ischemic heart disease $(\mathrm{P}=0.024)$ compared to patients not receiving a pacemaker.

\section{Limitations}

One quarter of the new AF cases were identified at the first registration, so they would have been detected with routine care involving a pulse check and/or ECG. The additional value of the handheld ECG with intermittent registrations is therefore in the detection of the remaining patients.

Seven out of 35 AF patients were confirmed only after an additional 24-hour Holter ECG. This makes it more difficult to say how many patients would have been found after a shorter screening of two weeks (decisions about doing an additional Holter were only made after the whole four-week period). Nevertheless only 24 Holter recordings were needed to find seven more AF cases, which makes this kind of intermittent screening still very efficient.

We used registrations of only 10 seconds due to the limited capacity of the handheld device; we do not know at present whether 30-second registrations of $\mathrm{AF}$, as used in guidelines, are more relevant. The AF definition used by the European Society of Cardiology in its Guidelines from 2010 - Any arrhythmia that has the ECG characteristics of AF and lasts sufficiently long for a 12- 
lead ECG to be recorded, or at least $30 \mathrm{~s}$ on a rhythm strip, should be considered as AF' - is not empirical, but based on consensus [9]. Standard 12-lead ECG is a 10second strip and diagnosis of AF based on a 10-second 12-lead resting ECG is used in other recent studies [6].

Providing lifelong anticoagulation to someone with a single 10-second episode of AF is definitely a leap too far at this stage. The patients in this study, however, had AF on more than $30 \%$ of their registrations on average (almost three minutes in a total registration time of only eight and a half minutes). Only AF registrations that lasted the full 10 seconds were counted as AF. How long these episodes lasted in reality is impossible to say. Two patients had a single 10-second episode of AF, which could not be reproduced during follow-up. It is therefore important in future screening projects that patients complete the screening period even if AF is diagnosed and further confirmatory testing will be required in many patients.

A disadvantage of the handheld ECG device is that only lead I is recorded, which sometimes makes it difficult to distinguish (1:1 and 2:1 blocked) atrial flutter from a regular supraventricular re-entry tachycardia such as AV-nodal re-entry tachycardia, which might have resulted in underdetection of atrial flutter [25]. At the same time, we cannot exclude the possibility of some cases with short runs of atrial tachycardia being mislabelled as AF because of the short 10-second recording time [25]. Ideally, this study should have been performed along with a more continuous monitoring device to help assess the accuracy of the outcomes.

\section{Conclusions}

Opportunistic screening with intermittent handheld ECG registration over four weeks showed a detection rate of $3.8 \%$ of previously undiagnosed AF, in a population $(\mathrm{n}=$ 928) of relatively healthy and relatively young, out-of-hospital patients having at least one additional risk factor for stroke. This study shows very high compliance suggesting that opportunistic screening using this method could be a feasible technique for detection of AF.

\section{Competing interests}

The authors declare that they have no competing interests. Neither Dr. Tijn Hendrikx, Dr. Rolf Hörnsten, Prof. Mårten Rosenqvist nor Dr. Herbert Sandström has any commercial interests in Zenicor Medical Systems AB.

\section{Authors' contributions}

$\mathrm{TH}$ took part in conceiving and designing the research, acquiring data, analysed and interpreted data, performed statistical analysis and drafted and revised the paper. He is guarantor. $\mathrm{RH}$ took part in acquiring data, analysing and interpreting data and revising the manuscript. HS took part in conceiving and designing the research, handled funding and supervision and made critical revisions of the manuscript. MR conceived and designed the research, handled funding and supervision and made critical revisions of the manuscript. All authors read and approved the final manuscript.

\section{Acknowledgments}

Eva Skoglund, diabetes nurse, Lycksele Health Care Centre; Carina MörtzellKarlsson, reg. nurse; Linda Hjalmarsson, reg. nurse, Storuman Health Care Centre; Karin Gebart-Hedman, reg. nurse, Storuman; Eva Nordlinder, reg. nurse, Bureå/Skelleftehamn Health Care Centre; Elisabeth Königsson, reg. nurse, Vindeln Health Care Centre; Gunborg Lundström, reg. nurse, Vindeln Health Care Centre; Irene Backlund, reg. nurse, Ersboda Health Care Centre, Umeå; Runa Sundelin, reg. nurse, Sköndal Health Care Centre, Årsta Health Care Centre, South Hospital, Stockholm; Lisa Bastani, reg. nurse, Stockholm Heart Centre; Professor Per Wester, Umeå Stroke Center, Dept Public Health and Clinical Medicine, Umeå University.

\section{Funding}

This study was supported by grants from Umeå University Hospital and Vinnova.

Zenicor Medical Systems AB, Stockholm has supported the study by providing handheld ECG devices (Zenicor EKG ${ }^{\oplus}$ ) at a reduced price.

\section{Author details}

'Department of Public Health and Clinical Medicine, Family Medicine, Umeå University, SE-901 87, Umeå, Sweden. ${ }^{2}$ Clinical Physiology, Heart Centre and Department of Surgical and Perioperative Science, Umeå University, SE-901 87, Umeå, Sweden. ${ }^{3}$ Department of Clinical Science, Karolinska Institutet, Danderyds Sjukhus SE-182 88, Stockholm, Sweden.

Received: 10 January 2013 Accepted: 3 June 2013

Published: 10 June 2013

\section{References}

1. Kannel WB, Wolf PA, Benjamin EJ, Levy D: Prevalence, incidence, prognosis, and predisposing conditions for atrial fibrillation: populationbased estimates. Am J Cardiol 1998, 82(8A):2N-9N.

2. Furberg CD, Psaty BM, Manolio TA, Gardin JM, Smith VE, Rautaharju PM: Prevalence of atrial fibrillation in elderly subjects (the Cardiovascular Health Study). Am J Cardiol 1994, 74(3):236-241.

3. Go AS, Hylek EM, Phillips KA, Chang Y, Henault LE, Selby JV, Singer DE: Prevalence of diagnosed atrial fibrillation in adults: national implications for rhythm management and stroke prevention: the AnTicoagulation and Risk Factors in Atrial Fibrillation (ATRIA) Study. JAMA 2001, 285(18):2370-2375.

4. Heeringa J, van der Kuip DA, Hofman A, Kors JA, Van Herpen G, Stricker BH, Stijnen T, Lip GY, Witteman JC: Prevalence, incidence and lifetime risk of atrial fibrillation: the Rotterdam study. Eur Heart J 2006, 27(8):949-953.

5. Murphy NF, Simpson CR, Jhund PS, Stewart S, Kirkpatrick M, Chalmers J, MacIntyre K, McMurray JJ: A national survey of the prevalence, incidence, primary care burden and treatment of atrial fibrillation in Scotland. Heart 2007, 93(5):606-612.

6. Andersson P, Londahl M, Abdon NJ, Terent A: The prevalence of atrial fibrillation in a geographically well-defined population in Northern Sweden: implications for anticoagulation prophylaxis. J Intern Med 2012, 272(2):170-176.

7. Wolf PA, Abbott RD, Kannel WB: Atrial fibrillation as an independent risk factor for stroke: the Framingham Study. Stroke 1991, 22(8):983-988.

8. Gage BF, Waterman AD, Shannon W, Boechler M, Rich MW, Radford MJ: Validation of clinical classification schemes for predicting stroke: results from the National Registry of Atrial Fibrillation. JAMA 2001, 285(22):2864-2870.

9. Camm AJ, Kirchhof P, Lip GY, Schotten U, Savelieva I, Ernst S, Van Gelder IC, Al-Attar N, Hindricks G, Prendergast B, et al: Guidelines for the management of atrial fibrillation: the Task Force for the Management of Atrial Fibrillation of the European Society of Cardiology (ESC). Eur Heart J 2010, 31(19):2369-2429.

10. Eriksson M, Stecksen A, Glader EL, Norrving B, Appelros P, Hulter Asberg K, Stegmayr B, Terent A, Asplund K: Discarding heparins as treatment for progressive stroke in Sweden 2001 to 2008. Stroke 2001-2008, 41(11):2552-2558.

11. Flaker GC, Belew K, Beckman K, Vidaillet H, Kron J, Safford R, Mickel M, Barrell P: Asymptomatic atrial fibrillation: demographic features and prognostic information from the Atrial Fibrillation Follow-up Investigation of Rhythm Management (AFFIRM) study. Am Heart J 2005, 149(4):657-663. 
12. Page RL, Wilkinson WE, Clair WK, McCarthy EA, Pritchett EL: Asymptomatic arrhythmias in patients with symptomatic paroxysmal atrial fibrillation and paroxysmal supraventricular tachycardia. Circulation 1994, 89(1):224-227.

13. Healey JS, Connolly SJ, Gold MR, Israel CW, Van Gelder IC, Capucci A, Lau $C P$, Fain $E$, Yang $S$, Bailleul $C$, et al: Subclinical atrial fibrillation and the risk of stroke. N Engl J Med 2012, 366(2):120-129.

14. Friberg L, Hammar N, Rosenqvist M: Stroke in paroxysmal atrial fibrillation: report from the Stockholm Cohort of Atrial Fibrillation. Eur Heart J 2010, 31(8):967-975.

15. Banerjee A, Taillandier S, Olesen JB, Lane DA, Lallemand B, Lip GY, Fauchier L: Pattern of atrial fibrillation and risk of outcomes: The Loire Valley Atrial Fibrillation Project. Int J Cardiol 2012, doi:10.1016/j.jicard.2012.06.118.

16. Hohnloser SH, Pajitnev D, Pogue J, Healey JS, Pfeffer MA, Yusuf S, Connolly $\mathrm{SJ}$, Investigators AW: Incidence of stroke in paroxysmal versus sustained atrial fibrillation in patients taking oral anticoagulation or combined antiplatelet therapy: an ACTIVE W Substudy. J Am Coll Cardiol 2007, 50(22):2156-2161.

17. Liao J, Khalid Z, Scallan C, Morillo C, O'Donnell M: Noninvasive cardiac monitoring for detecting paroxysmal atrial fibrillation or flutter after acute ischemic stroke: a systematic review. Stroke 2007, 38(11):2935-2940.

18. Tagawa M, Takeuchi S, Chinushi M, Saeki M, Taniguchi Y, Nakamura Y, Ohno H, Kitazawa K, Aizawa Y: Evaluating patients with acute ischemic stroke with special reference to newly developed atrial fibrillation in cerebral embolism. Pacing Clin Electrophysiol 2007, 30(9):1121-1128.

19. Douen A, Pageau N, Medic S: Usefulness of cardiovascular investigations in stroke management: clinical relevance and economic implications. Stroke 2007, 38(6):1956-1958.

20. Doliwa Sobocinski P, Anggardh Rooth E, Frykman Kull V, von Arbin M, Wallen $\mathrm{H}$, Rosenqvist M: Improved screening for silent atrial fibrillation after ischaemic stroke. Europace 2012, 14(8):1112-1116.

21. Fitzmaurice DA, Hobbs FD, Jowett S, Mant J, Murray ET, Holder R, Raftery JP, Bryan S, Davies M, Lip GY, et al: Screening versus routine practice in detection of atrial fibrillation in patients aged 65 or over: cluster randomised controlled trial. BMJ 2007, 335(7616):383.

22. Hobbs FD, Fitzmaurice DA, Mant J, Murray E, Jowett S, Bryan S, Raftery J, Davies M, Lip G: A randomised controlled trial and cost-effectiveness study of systematic screening (targeted and total population screening) versus routine practice for the detection of atrial fibrillation in people aged 65 and over. The SAFE study. Health Technol Assess 2005, 9(40):1-74. iii-iv, ix-X.

23. Morgan $S$, Mant D: Randomised trial of two approaches to screening for atrial fibrillation in UK general practice, The British journal of general practice. J R Coll Gen Pract 2002, 52(478):373-374. 377-380.

24. Reiffel JA, Schwarzberg R, Murry M: Comparison of autotriggered memory loop recorders versus standard loop recorders versus 24-hour Holter monitors for arrhythmia detection. Am J Cardiol 2005, 95(9):1055-1059.

25. Doliwa PS, Frykman V, Rosenqvist M: Short-term ECG for out of hospital detection of silent atrial fibrillation episodes. Scand Cardiovasc J 2009, 43(3):163-168.

26. Ziegler PD, Glotzer TV, Daoud EG, Singer DE, Ezekowitz MD, Hoyt RH, Koehler JL, Coles I Jr, Wyse DG: Detection of previously undiagnosed atrial fibrillation in patients with stroke risk factors and usefulness of continuous monitoring in primary stroke prevention. Am J Cardiol 2012, 110(9):1309-1314.

27. Rosenberg MA, Samuel M, Thosani A, Zimetbaum PJ: Use of a noninvasive continuous monitoring device in the management of atrial fibrillation: a pilot study. Pacing Clin Electrophysiol 2013, 36(3):328-333.

28. Friberg L, Engdahl J, Frykman V, Svennberg E, Levin LA, Rosenqvist M: Population screening of 75- and 76-year-old men and women for silent atrial fibrillation (STROKESTOP). Europace 2013, 15(1):135-40.

doi:10.1186/1471-2261-13-41

Cite this article as: Hendrikx et al: Screening for atrial fibrillation with baseline and intermittent ECG recording in an out-of-hospital population. BMC Cardiovascular Disorders 2013 13:41.

\section{Submit your next manuscript to BioMed Central and take full advantage of:}

- Convenient online submission

- Thorough peer review

- No space constraints or color figure charges

- Immediate publication on acceptance

- Inclusion in PubMed, CAS, Scopus and Google Scholar

- Research which is freely available for redistribution

Submit your manuscript at www.biomedcentral.com/submit
( BioMed Central 